\title{
OFICINA animAÇÃO: EXPERIÊNCIA PRÁTICA SOBRE O USO DO CINEMA EM UMA ESCOLA DA REDE MUNICIPAL DE PRESIDENTE PRUDENTE (SP)
}

\author{
Gabriel Batista Mota, Gabriela das Graças Oliveira Leal, Thaisa Sallum Bacco \\ Universidade do Oeste Paulista - UNOESTE, Faculdade de Comunicação Social, Presidente Prudente, SP. E-mail: \\ thaisa@unoeste.br
}

\section{RESUMO}

Este artigo discute as relações entre o Cinema e a Educação. A finalidade é aplicar a linguagem cinematográfica na educação básica e, assim, apresentar uma experiência de uso do vídeo enquanto ferramenta pedagógica no cenário educacional de Presidente Prudente (SP). Para tanto, apresenta-se o relato de uma oficina audiovisual, realizada com crianças de 10 e 11 anos da E. M. Profa. Odette Duarte da Costa, que resultou na produção de curtas-metragens utilizando a técnica do stop motion.

Palavras-chave: Cinema na Educação. Cinema na escola. Linguagem Audiovisual. Stop Motion. Ensino Básico.

\section{AanimATION WORKSHOP: PRACTICAL EXPERIENCE ON THE USE OF CINEMA IN A SCHOOL OF THE MUNICIPAL NETWORK OF PRESIDENTE PRUDENTE - SP}

\begin{abstract}
This article discusses the relationship between Cinema and Education. The purpose is to apply cinematographic language in basic education and present an experience of using video as a pedagogical tool in the educational scenario of Presidente Prudente - SP. Therefore, we present the report of an audiovisual workshop, carried out with children of 10 and 11 years old of E.M. Profa. Odette Duarte da Costa, which resulted in stop motion short films.
\end{abstract}

Keywords: Cinema in Education. Cinema at school. Audiovisual Language. Stop Motion. Elementary school.

\section{INTRODUÇÃO}

A Comunicação, campo de domínio dos jornalistas, é uma área que pode oferecer contribuição à Educação, pois possibilita a inserção de ferramentas pouco usuais ao método pedagógico tradicional, como a linguagem audiovisual, no qual o cinema se sobressai por oferecer uma alternativa aos discentes de inserirse ao conteúdo proposto com mais facilidade já que o Brasil, segundo Pfromm Netto (2011), apresenta, assim como a maior parte das demais sociedades ocidentais, uma afinidade mais forte com o universo imagético.

Essa relação entre a Comunicação e a Educação é reforçada, ainda mais, ao inserirmos à discussão a lei federal no 13.006 , sancionada em 26 de junho de 2014 pela então presidente Dilma Rousseff, que determina que todas as escolas de educação básica do Brasil acrescentem em seu componente curricular a exibição de duas horas mensais de cinema nacional (BRASIL. Congresso Nacional, 2014). Segundo Fresquet e Migliorin (2015), essa lei viabiliza o acesso das crianças e suas famílias ao cinema, sabendo que o contato com novas formas de expressão permite a concepção de novos conhecimentos. Os autores $(2015$, p.5) ainda afirmam que "[...] a exibição de filmes nacionais seria apenas um indicativo e não uma obrigatoriedade" ao sistema educacional brasileiro.

A ligação entre o cinema e a Educação é discutida há décadas. Duarte (2009, p.70) explica que "Embora valorizado, o cinema ainda não é visto pelos meios educacionais como fonte de conhecimento" e por esse motivo o audiovisual é um campo ainda pouco explorado pelos professores e estudantes de escolas brasileiras, mesmo que "Em sociedades audiovisuais como a nossa, o domínio dessa linguagem é requisito 
fundamental para se transitar bem pelos mais diferentes campos sociais" (DUARTE, 2009, p.14).

Pires (2008, p.16-17) aponta que esse uso da mídia no método de ensino abranda a resistência das instituições tradicionais às novas formas de diálogo. Essa inserção da linguagem audiovisual na Educação é necessária, porque "Muitos de nossos alunos dedicam mais horas aos novos recursos tecnológicos - consumindo imagens e mensagens - do que às atividades em sala de aula" (MORAES, 2005, p.298).

Desde o início do uso do que era conhecido como cinematógrafo - nome dado pelos irmãos Lumière ao inventarem o conceito do cinema - pesquisadores, educadores e psicólogos estudavam a eficácia do uso da linguagem audiovisual no ensino básico, mas é necessário enquadrar o uso dessas tecnologias comunicacionais ao cotidiano, pois a influência do audiovisual é "[...] pequena quando o conhecimento prévio é inadequado ou quando seu conteúdo se opõe às atitudes e motivações da audiência" (PFROMM NETTO, 2011, p.109). Ele deve ser ensinado como qualquer outro código, para que seja colocado em prática, já que, como aponta Canto (2013, p.138), "A linguagem visual é tão legítima como qualquer língua; [...] aprender a sua gramática é um passo fundamental para compreendermos e podermos frui-la".

É importante ressaltar que a linguagem audiovisual possibilita a produção de conteúdo por meio de suas diferentes vertentes. Entre elas, está a animação que, pela eficiência ilustrativa, chama atenção não só de crianças, mas de adultos, ganhando evidência na atualidade. Uma das técnicas da animação, o stop motion, segundo Canto (2013), pode desencadear o desenvolvimento do pensamento. Desta forma, considera-se importante discutir as interfaces entre as duas áreas do conhecimento.

\section{CINEMA E EDUCAÇÃO}

Embora o francês Georges Meliès ${ }^{1}$, assim como o fotógrafo Muybridge ${ }^{2}$, seja considerado um dos criadores do cinema como espetáculo, pois "[...] realizou vários filmes produzidos com

\footnotetext{
${ }^{1}$ Marie Georges Jean Méliès nasceu em Paris, em 1861 e faleceu em 1938. Jovem, aprendeu truques de mágica, que também é chamada de ilusionismo. Méliès é considerado o "pai dos efeitos especiais" (ANTÔNIO, 2012).

${ }^{2}$ Eadweard James Muybridge foi um fotógrafo conhecido por suas experiências com várias câmeras. Tinha como objetivo captar os movimentos imperceptíveis na visão normal (FABRIS, 2004, p.52).
}

cenários e efeitos especiais, empregou atores e teve intenção de contar uma história, não registrando apenas imagens cotidianas", o conceito dessa arte, como a conhecemos hoje, que a atribui a prática da exibição de filmes e que surgiu em dezembro de 1895, é atribuído aos irmãos Louis e Auguste Lumière (NAPOLITANO, 2006, p.69). Os franceses projetaram longasmetragens em seu país de origem, ato este que surpreendeu os espectadores, pois agora "[...] as pessoas tinham a possibilidade de ver imagens reais em movimento, projetadas sobre uma tela grande" (NAPOLITANO, 2006, p.68-69). O acontecimento contou com a presença de 33 pessoas no salão do Gran Café, no no 14 do Boulevard des Capucines, em Paris, e mesmo sem a presença da imprensa "[...] o boca a boca espalhou a novidade e, em breve, haveria mais de duas mil pessoas, todos os dias, à porta do salão, aguardando a chance de ver aquelas curiosas fotografias animadas" (DUARTE, 2009, p.21).

Duarte $(2009$, p.34) afirma que o cinema nasceu com pretensões acadêmicas já que pode oferecer, quando usado corretamente, um complemento ao entendimento do espectador e possibilita, quando se conhece a linguagem cinematográfica, melhorar a forma com que vemos os filmes. A autora (2009, p.28) lembra que o Brasil conheceu o cinematógrafo em 1896 e dois anos depois já criava sua própria identidade cinematográfica. Nesse período, pelo fato de existirem pesquisas envolvendo o cinema e a aprendizagem, ele foi censurado pelo sistema educacional de diretrizes católicas, pois a Igreja "[...] acreditava que os filmes poderiam deformar as mentes, por serem apreciados, antes de tudo, pela via da emoção" (MOGADOURO, 2014, p.4).

Mesmo com os trabalhos cinematográficos sendo censurados pela Igreja Católica, esse recurso continuaria a ser analisado para o seu uso enquanto ferramenta pedagógica, uma vez que, como afirma Duarte (2009, p.72), o cinema também funciona como porta de entrada para novos conhecimentos, podendo "[...] despertar o interesse e estimular a curiosidade em torno de temas e problemas que, muitas vezes, sequer seriam levados em conta".

Assim como Duarte (2009, p.72), Pfromm Netto (2011, p.109) assegura que "Desde os tempos do cinema mudo, numerosos psicólogos e educadores realizaram pesquisas científicas sobre os filmes como meio de aprendizagem e ensino". O autor (2011, p.106) ainda garante que, 
além de estar presente no campo da arte e do entretenimento, o cinema "[...] tem sido amplamente usado para propósitos de documentação, demonstração, ilustração, pesquisa, educação e treinamento".

Quanto a sua relação com a Educação, Almeida, Falcão e Citelli (2012, p.1) são enfáticos ao declararem que o Cinema e a Educação são áreas cada vez mais interligadas e "[...] não é mais plausível hoje discutir questões relacionadas à área da Educação sem pensar o campo da Comunicação".

A relação entre o cinema e a Educação surgiu, de fato, no início do século $X X$, quando, segundo Pfromm Netto (2011, p.113), “[...] companhias [foram] criadas especialmente para produzir e distribuir filmes educativos para escolas, igrejas, clubes, instituições políticas e organizações industriais [...]". Um desses primeiros filmes pedagógicos, que se tem registro, foi produzido na Alemanha e França, nos séculos XIX e XX, para o ensino em cursos de Medicina, situação semelhante ao Brasil, pois o uso de produções cinematográficas, com fins educacionais, aconteceu em 1907, quando o médico cirurgião brasileiro, Chapot-Prevost ${ }^{3}$, separou - e registrou em filme - duas irmãs xipófogas no Rio de Janeiro (PFROMM NETTO, 2011, p.116).

Para Napolitano (2006, p.15), uma das formas de estimular o uso do cinema como ferramenta pedagógica é o fato de que a linguagem cinematográfica, convida, de forma visual, os estudantes mais desinteressados à leitura. Já Duarte $(2009$, p.16) acredita que essa linguagem é inserida na Educação a partir do momento em que é necessária a compreensão da produção de padrões estéticos e também da socialização entre diferentes povos, culturas, valores e interesses. A autora (2009, p.14) ainda observa que "Ir ao cinema, ver filmes em salas de exibição é um hábito que precisa ser aprendido [...]", pois a falta do contato com este tipo de linguagem dificulta a formação, visual e estética, dos espectadores.

Fantin (2006, p.140) acrescenta que:

Considerar o cinema como um meio significa que a atividade de contar histórias com imagens,

\footnotetext{
${ }^{3}$ Eduardo Chapot-Prevost nasceu em 25 de junho de 1864 e morreu em 19 de outubro de 1907. Também foi o pioneiro no ensino de histologia e da cirurgia. Ficou famoso como professor e cirurgião em 1900 pela operação da primeira separação de pacientes xipófagas (FERREIRA, 1989, p.52).
}

sons e movimentos pode atuar no âmbito da consciência do sujeito e no âmbito sóciopolítico-cultural, configurando-se num formidável instrumento de intervenção, de pesquisa, de comunicação, de educação e de fruição.

O uso consciente do cinema na Educação pode, de acordo com Pfromm Netto (2011, p.109), trazer ganhos a todos. Ainda segundo o autor (2011, p.109), "Quando filmes efetivos e apropriados são usados de modo adequado, as pessoas aprendem mais em menos tempo e são capazes de reter o que aprenderam".

Para regularizar a exibição do cinema na sala de aula, foi criado o Instituto Nacional de Cinema Educativo (INCE) e, como relatam Bacco e Lima (2012, p.5), este fato deu-se em 1936, como prova de que o "[...] cinema nas escolas se configura como política pública, e ganha status oficial de cinema educativo".

Embora a aproximação entre o cinema e a escola seja necessária, é importante observar que a linguagem audiovisual não colabora, sozinha, com o campo educacional, já que que "[...] o cinema como simples representação ou ilustração do passado ou como pretexto para as demais atividades não vai contribuir para a formação do cidadão-crítico do século XXI" (BACCO; LIMA, 2012, p.13).

Após a compreensão da relação entre o cinema e a Educação, o próximo passo para a aquisição dessa linguagem como ferramenta pedagógica é inserir, no dia-a-dia educacional de uma sala e/ou escola - por um determinado período de tempo -, o filme de animação, uma vertente do cinema, como forma de aprofundar ainda mais os conhecimentos dessa arte. Para esta inserção, entre os gêneros do cinema, escolheu-se o filme de animação por estar presente na vida das crianças. Uma opção para esta etapa é o stop motion, uma vertente da animação que pode ser aplicada em diferentes públicos e situações.

\section{FILME DE ANIMAÇÃO}

Conhecer sobre a história do filme de animação é significante para o uso do audiovisual. Derivada do verbo latino animare ("dar vida a"), de acordo com Lucena Júnior (2011, p.28), a palavra animação só passou a ser empregada, para descrever figuras em 
movimento, no século XX. Magalhães (2015, p.11) acrescenta que o gênero é "[...] a arte de conferir a ilusão de vida, através do movimento, a objetos inanimados".

A prática de conceder animação, por meio do movimento, foi criada no século XVIII, pelo cientista holandês Pieter van Musschenbroek $^{4}$ ao demonstrar que um disco girava com imagens em sequências produzia a ilusão de mobilidade (LUCENA JÚNIOR, 2011, p.30-31).

No ano de 1891, Thomas Edison ${ }^{5}$ e William Dickson ${ }^{6}$ desenvolveram o kinetoscópio. O equipamento permitia a observação de, apenas, uma pessoa por vez. Segundo Lucena Júnior (2011, p.39-40), o artefato "Tinha um visor com lentes. Dentro havia um filme com perfurações laterais, que serpenteava em ziguezague, numa exibição sem fim cujo ciclo tinha 25 segundos".

Sabe-se que, em 1895, os irmãos Lumière exibiram as primeiras projeções graças ao aprimoramento do aparelho de Thomas Edison. Para Lucena Júnior (2011, p.47), o cinematógrafo servia tanto para projetar quanto para filmar, com isso "Não demorou para que também começassem a surgir as séries cinematográficas $[\ldots]^{\prime \prime}$.

A ilusão de movimento que se conhece como cinema, segundo Magalhães (2015, p.14), é uma das várias projetadas por meio da arte da animação, pois "[...] foi a primeira a se tornar popular e estabelecer uma linguagem para a nossa expressão através das imagens em movimento".

A princípio, o desenho que se movimentava fazia parte da nova magia do cinema, recorda Lucena Júnior (2011, p.48-49). Ainda de acordo o autor, de 1908 a 1917, a animação deixou de ser uma inovação para os espectadores, em relação à tecnologia, e passou a ser um elemento, independente, existente na

\footnotetext{
${ }^{4}$ Pieter van Musschenbroek foi responsável em produzir a ilusão de movimento, em 1736, ano da primeira exibição animada (FOSSATTI, 2009, p.3).

${ }^{5}$ Thomas Alva Edison patenteou o desenvolvimento de diversos dispositivos de grande interesse industrial, como baterias, luzes e energia elétrica, toca-discos e gravação de sons, cimento, mineração, imagens em movimento, telégrafos e telefones (BARKSDALE, 2012).

${ }^{6}$ William Kennedy Laurie Dickson foi um dos inventores do kinetoscópio, que era um aparelho que permitia a observação de apenas uma pessoa por vez, não sendo destinado à projeção (LUCENA JÚNIOR, 2011, p.39-40).
}

sociedade. Fantasmagorie (1908), de Émile Cohl ${ }^{7}$, é considerado o primeiro desenho animado de verdade (LUCENA JÚNIOR, 2011, p.50).

Com o decorrer do tempo, o procedimento de criação de filmes de animação transformou-se devido ao avanço tecnológico. Lucena Júnior (2011, p.221) explica que "[...] a computação aparece como a primeira grande técnica a transcender os métodos tradicionais de produção gráfica". Segundo o autor (2011, p.206), “[...] 1960 está para animação computadorizada assim como o período que vai de 1900 a 1910 se coloca para a animação tradicional [...]", quando as técnicas mais simples tornam-se intensos experimentos e descobertas.

Em 1970, já se podia articular uma classificação da animação realizada em sistemas digitais e em relação ao trabalho computadorizado tem-se a animação em 2D e 3D (LUCENA JÚNIOR, 2011, p.312). Com o desenvolvimento dos recursos tecnológicos do computador, ainda de acordo com o autor (2011, p.438), "[...] as iniciativas realmente válidas de criação visual [...] tornaram-se possíveis pela incorporação nos sistemas digitais [...]".

A perspectiva no 2D é composta de linhas bem claras, visíveis e duas características chamam a atenção, como "[...] o conceito de célula transparente (acetato) e a definição do caminho da ação (motion path), trazidas da animação tradicional" (LUCENA JÚNIOR, 2011, p.251, grifo do autor).

Averiguou-se, em 1960, a aquisição dos conceitos teóricos e práticos dos gráficos tridimensionais, ou seja, o 3D. Segundo Lucena Júnior (2011, p.282), tanto em sistemas no 3D quanto $2 \mathrm{D}$, as instruções são distintas e, por isso, é necessário ter atenção ao explorar um novo meio.

\section{A TÉCNICA DO STOP MOTION}

Dentre as técnicas cinematográficas, o stop motion, segundo Nisio (2011, p.16), consiste em fotografar um objeto e/ou pessoa, quadro a quadro e quando essas imagens são colocadas em sequência, geram a ideia de movimento.

Magalhães (2015, p.80) acrescenta que é preciso ter cuidado e atenção no momento de fotografar para não causar nenhum defeito na animação, uma vez que, cada segundo do audiovisual produzido em stop motion costuma

\footnotetext{
${ }^{7}$ Émile Eugène Jean Louis Courtet, popularmente conhecido como Émile Cohl, é considerado "pai do desenho animado", por ser o pioneiro na produção do gênero (CANTO, 2016, p.80).
} 
ter 24 quadros, o que torna "a animação muito próxima a do cinema ao vivo, [...] pois nele se aplicam as mesmas técnicas de iluminação e filmagem de um filme com atores reais" (MAGALHÃES, 2015, p.80).

A "imagem com vida" tem algumas vertentes adotadas para melhorar a técnica da animação. Nisio (2011, p.19) menciona quatro destes recursos, sendo eles Claymation, Pixilation, Claypainting e Time-lapse.

Dentre os artifícios citados, o mais popular é o Claymation, pois, segundo Nisio (2011, p.19-20), usam-se materiais flexíveis, como barro e massinha para constituir o ambiente que acerca a animação.

O Claypaiting, de acordo com o autor (2011, p.20), é uma variante do Claymation, uma vez que, caminha entre as três técnicas de animação, que são "[...] a animação de barro, a animação tradicional e a animação de recortes".

Outra técnica do stop motion é a Pixilation, na qual seres humanos são usados ao invés de objetos, "[...] consiste na animação de pessoas ou animais vivos" (NISIO, 2011, p.20).

Quando a intenção é dar velocidade às imagens, ainda mais que o real, usa-se a vertente de Time-lapse, conforme Nisio (2011, p.19), é "[...] uma variação bem distante da técnica, mas, ainda assim, associada à stop motion". Magalhães (2015, p.84) acrescenta que nessa técnica "[...] se utiliza o princípio do stop-motion: tirar fotos sucessivas e ir mudando a posição dos objetos filmados".

A animação por meio do stop motion engloba saberes e ideias. Para Canto (2013, p.141), esse recurso desenvolve a percepção e o raciocínio complexo e traz a lembrança do estético. A autora acrescenta que é fundamental a seleção e interpretação do storyboard, além da montagem e criação da cena, bonecos e figuras, que requerem conhecimentos distintos por parte dos produtores do vídeo (CANTO, 2013, p.141).

Compreendendo a relação entre o cinema e a Educação, o filme de animação e a técnica do stop motion, os autores propuseram como sugestão a produção de curtas-metragens, em stop motion, em uma escola municipal de Presidente Prudente (SP). A proposta, intitulada "Oficina animAÇÃO", trata-se de um projeto piloto, voltada para ensino básico, que aborda a importância da inserção, produção e discussão sobre conteúdos audiovisuais no contexto escolar (MOTA et al., 2016).

\section{Oficina animAÇÃo}

A "Oficina animAÇÃO" é resultado de uma pesquisa científica intitulada "O uso do filme de animação como ferramenta pedagógica no ensino básico de Presidente Prudente (SP)", elaborada em 2016 pelos graduandos do curso de Jornalismo da Faculdade de Comunicação Social "Jornalista Roberto Marinho" (Facopp) da Universidade do Oeste Paulista (Unoeste) de Presidente Prudente (SP), Gabriel Batista Mota, Gabriela das Graças Oliveira Leal, Isabelle Laís Garcia Furuya, João Pedro Rossini Leite Silva, Murilo de Oliveira e Roberto Kawasaki Serafini, sob a orientação da professora Dra. Thaisa Sallum Bacco (MOTA et al., 2016).

A oficina foi aplicada no segundo semestre de 2016 na E. M. Profa. Odette Duarte da Costa, localizada no Jardim Morada do Sol. Dentre as turmas, a participante foi a do 5o ano $B$, na época composta por 29 crianças, sendo 17 meninos (58\%) e 12 meninas (42\%). A faixa etária era de $10(28 \%)$ e 11 anos (72\%) (MOTA et al., 2016).

É importante ressaltar que, antes da aplicação da oficina, as crianças foram até o cinema local para assistirem ao filme "Procurando Dory" ${ }^{8}$, pois o contato dos estudantes com o ambiente cinematográfico é importante para que tivessem uma sensação diferente ao assistirem aos filmes em uma tela maior.

Para o desenvolvimento da oficina, os seguintes materiais didáticos foram produzidos: uma cartilha "animAÇÃO", com objetivo de introduzir e fortalecer o conteúdo desenvolvido em sala de aula discutindo o processo de produção fílmica e também apresenta orientações para ajudar o(s) docente(s) em atividades de natureza fílmica. Já o conteúdo audiovisual, produzido e apresentado em videoaulas, serviu para contextualizar sobre o cinema, o gênero animação e a técnica do stop motion.

Após a apresentação do projeto na escola, junto com a professora da sala, uma animação em stop motion experimental foi produzida, cujo o objetivo era introduzir a docente nos conhecimentos práticos da linguagem fílmica. Para Napolitano (2006, p.57), é importante que o professor tenha conhecimento sobre o recurso audiovisual que fará uso, pois

\footnotetext{
${ }^{8} \mathrm{O}$ filme narra a história de uma peixe azul que possui perda de memória e tenta reencontrar seus pais (PROCURANDO DORY, 2016).
} 
“[...] não precisa ser crítico profissional de cinema para trabalhar com filmes na sala de aula. Mas o conhecimento de alguns elementos de linguagem cinematográfica vai acrescentar qualidade ao trabalho".

Depois de conhecer a sala e a produção do audiovisual em stop motion, deu-se início a oficina com as crianças. Com a ajuda da professora da sala em questão, cinco grupos foram formados, cada uma das equipes deveria escolher, de acordo com o conteúdo programático, um tema a ser trabalhado e o nome que daria ao grupo.

Com o tema escolhido, iniciou-se a orientação sobre o processo de produção de um filme, a partir das videoaulas, as etapas de préprodução, produção e pós-produção, que foram trabalhadas detalhadamente em sala de aula com as crianças.

$\mathrm{Na}$ fase de pré-produção, todas as equipes foram orientadas, tanto pelos graduandos como pela professora, sobre seus temas e, desta forma, concluíram a construção de suas ideias a partir de várias pesquisas. Os grupos produziram um storyboard, que serviu de orientação para a produção dos materiais necessários para o stop motion e escolheram, de acordo com a preferência de cada um, se iriam trabalhar com desenhos, massinhas, pessoas ou objetos. Todos os cinco grupos optaram pelo desenho, pois a sala possuía mais habilidade em pintar e desenhar.

A etapa de produção consistiu em transformar as ideias em materiais físicos. As equipes confeccionaram os desenhos e, em seguida, pintaram e recortaram. Após esse processo, foi realizada a gravação do filme. Sob a supervisão e auxílio dos pesquisadores, os grupos fotografaram suas animações em stop motion utilizando um tripé artesanal (feito com garrafa pet) e uma câmera Cyber-shot que, certamente, pode ser substituída por um celular.

A última etapa foi a pós-produção, momento para editar o conteúdo. A princípio, as crianças tiveram um pouco de receio $\mathrm{e}$ dificuldade, pois nunca haviam tido contato com softwares de edição de vídeo. Depois de algumas orientações, os estudantes começaram a participar mais e querer fazer suas próprias edições. Quatro audiovisuais, além das fotos, contavam com a narração das crianças e uma música tema, escolhida no banco de áudio disponível no YouTube.
Após finalizar as três etapas da produção de um audiovisual, reunidos em forma de roda de conversa, os cinco vídeos foram exibidos para toda a sala. Neste momento foi discutido com as crianças o que poderia ser melhorado nas próximas edições ou o que daria para acrescentar nos audiovisuais finalizados.

A roda de conversa possibilitou conhecer quais as conclusões que as crianças participantes do projeto tiveram. As mesmas apresentaram o interesse em produzir mais vídeos, porém com maior duração, além de evidenciarem a dificuldade em gravar o áudio do curta. Os participantes ainda ressaltaram o receio no momento de fotografar as histórias. Para o estudante João Paulo Martins $(2016)^{9}$, o seu maior obstáculo foi a etapa de gravar o áudio, que seria usado com off, "[...] eu até gostei, mas me atrapalhei na hora de gravar o áudio". Uma das equipes explicou que sentiu dificuldades na hora de fotografar, "[...] porque não podia mexer se não a foto iria sair 'faiscada"" (FRANCISCO, 2016) $)^{10}$. A estudante Beatriz Gonçalves (2016) ${ }^{11}$, contou que aprendeu "Como faz um vídeo e [...] o que é stop motion", assim como seus colegas Antony da Cruz $(2016)^{12}$ e Felipe da Silva $(2016)^{13}$.

Entretanto, o modo de preparação e elaboração das animações proporcionou discussões, além da linguagem cinematográfica, de outros assuntos normalmente não trabalhados em sala de aula. Despertou, por exemplo, o trabalho em equipe, o senso estético e crítico.

A "Oficina animAÇÃO" resultou, portanto, na produção de cinco curtas-metragens intitulados "A história do basquete", "O Tubarão Branco", "A regra do três", "As cores Super D+" e "Bob, o cãozinho", que foram exibidos à comunidade, discentes, docentes e gestão escolar, no 10 Festival de curtas-metragens da escola, que ocorreu no dia 11 de novembro de 2016. Na ocasião, a diretora, a professora da sala

\footnotetext{
9 Entrevista com João Paulo Martins, estudante da E. M. Profa. Odette Duarte da Costa. Entrevista sobre a oficina. Concedida a Gabriela Leal. 30 set. 2016.

${ }^{10}$ Entrevista com Silvia Francisco, estudante da E. M. Profa. Odette Duarte da Costa. Entrevista sobre a oficina. Concedida a João Pedro Rossini. 30 set. 2016.

11 Entrevista com Beatriz Gonçalves, estudante da E. M. Profa. Odette Duarte da Costa. Entrevista sobre a oficina. Concedida a Isabelle Garcia. 30 set. 2016.

${ }^{12}$ Entrevista com Antony da Cruz, estudante da E. M. Profa. Odette Duarte da Costa. Entrevista sobre a oficina. Concedida a Roberto Kawasaki. 30 set. 2016.

${ }^{13}$ Entrevista com Felipe da Silva, estudante da E. M. Profa. Odette Duarte da Costa. Entrevista sobre a oficina. Concedida a Gabriel Mota. 30 set. 2016.
} 
e a orientadora pedagógica da instituição ressaltaram a importância de projetos audiovisuais como esse, além de fortificar a pertinência de continuar aplicando o mesmo.

A secretária municipal da Educação, Ondina Barbosa Gerbasi, após a apresentação dos vídeos das crianças, constatou que houve desenvolvimento no quesito da leitura e interpretação e os envolvidos demonstraram satisfação ao decorrer do evento. "O fato de conseguirem motivar as crianças para que elas possam aprender mais e muito mais, porque vocês viram como elas vão ficando mais desenvoltas, vão lendo melhor, interpretando melhor, elas vão, inclusive, tendo uma autoestima desenvolvida" (GERBASI, 2016) ${ }^{14}$.

Todo o conteúdo audiovisual produzido em prol e no decorrer da "Oficina animAÇÃO", incluindo todos os curtas produzidos, encontra-se disponível na página do projeto no Facebook ${ }^{15}$. A página funcionou como um diário da aplicação da oficina na E. M. Profa. Odette Duarte da Costa.

\section{CONSIDERAÇÕES FINAIS}

Após o fim da "Oficina animação", os pesquisadores concluíram que é possível usar o filme de animação enquanto ferramenta pedagógica. Para tanto, é necessário, antes de tudo, capacitar todos os envolvidos que irão trabalhar no projeto, adequar, para cada faixa etária, a forma de se comunicar com estes sujeitos, além de selecionar conteúdos que estejam, é claro, dentro do currículo escolar.

Também é relevante trabalhar com temas de interesse do público-alvo, já que é fundamental planejar a melhor maneira de introduzir o conteúdo audiovisual na rotina pedagógica da turma e manter o compromisso, da responsabilidade social do Jornalismo, com o projeto proposto, atentando-se à interdisciplinaridade do trabalho.

Com esse estudo, considera-se que embora a carreira de jornalista se concentre na redação e em veículos de notícia, há outros caminhos de atuação para este profissional. Para a área da Educação, envolvendo o Jornalismo nas políticas e projetos públicos educacionais, a Comunicação pode oferecer novos recursos e ferramentas à prática pedagógica, como também

\footnotetext{
${ }^{14}$ Entrevista com Ondina Barbosa Gerbasi, secretária da Educação. Entrevista sobre o 1o Festival de curtas-metragens na E. M. Profa. Odette Duarte da Costa. Concedida a Isabelle Garcia. 11 nov. 2016.

${ }^{15}$ Disponível em: https://www.facebook.com/animacaooficina
}

a utilização da linguagem audiovisual, uma forma de comunicação universal e acessível a todos.

Por essa razão, os pesquisadores concluem que é de extrema importância discutir as relações entre Comunicação e Educação para a implantação de práticas no cotidiano escolar que promovam a reflexão, a partir do ensino básico, da prática audiovisual e sua relevância na sociedade atual.

\section{REFERÊNCIAS}

ALMEIDA, M.C. S. ; FALCÃO, S. P.; CITELLI, A. O. O cinema como instância formativa de professores, In: CONGRESSO BRASILEIRO DE CIENCIAS DA COMUNICAÇÃO, 35., 2012, Fortaleza. Anais eletrônicos... Fortaleza, Intercom, 2012. Disponível em: <http://www.intercom.org.br/papers/nacionais/ 2012/resumos/R7-0576-1.pdf>. Acesso em: 25 jul. 2016.

ANTÔNIO, D. 'Hugo Cabret' leva Méliès de volta ao cinema; confira filmes do cineasta. 2012. Disponível em:

<http://www1.folha.uol.com.br/folhinha/2012/0 2/1046567-hugo-cabret-leva-meliesde-volta-aocinema-confira-filmes-do-cineasta.shtml>. Acesso em: 21 set. 2016.

BACCO, T. S.; LIMA, C. M. Memória e Sociedade: a História do Cinema de Presidente Prudente (SP) nas Salas de Aula. In: CONGRESSO BRASILEIRO DE CIÊNCIAS DA COMUNICAÇÃO, 35., 2012,

Fortaleza. Anais eletrônicos... Fortaleza:

Intercom, 2012. Disponível em: <http://www.intercom.org.br/papers/nacionais/ 2012/resumos/R7-0904-1.pdf >. Acesso em: 22 maio 2016.

BARKSDALE, M. 10 invenções desconhecidas de Thomas Edison. 2012. Disponível em: $<$ http://ciencia.hsw.uol.com.br/10-invencoesdesconhecidas-de-thomas-edison.htm>. Acesso em: 22 set. 2016.

BRASIL. Congresso Nacional. Lei de Diretrizes e Bases da Educação Nacional. Lei n.o 13.006 de 26 de junho de 2014. Acrescenta $\S 80$ ao art. 26 da Lei $n$ ㅇ 9.394, de 20 de dezembro de 1996, que estabelece as diretrizes e bases da educação nacional, para obrigar a exibição de filmes de produção nacional nas escolas de educação básica. Diário Oficial da União, Brasília, DF, 27 de jun. 2014. Disponível em: <http://www2.camara.leg.br/legin/fed/lei/2014/I ei-13006-26-junho-2014778954publicacaooriginal-144445-pl.html>. Acesso em: 28 set. 2016. 
CANTO, A. Do texto ao stop-motion. Matéria-

Prima: Práticas Artísticas no Ensino Básico e Secundário, Lisboa, v. 1, n. 2, jul./dez., 2013. Disponível em: <http://repositorio.ul.pt/bitstream/10451/9994/ 2/ULFBA_PER_Ana\%20do\%20Canto.p df>. Acesso em: 14 mar. 2016.

CANTO, A. T. P. Animação no universo contemporâneo: o sincretismo dos desenhos animados e sua relação com o público infantil. Ícone, Porto Alegre, v. 1, n. 2, jul., 2016.

Disponível em:

<http://www.seer.ufrgs.br/index.php/icone/articl e/view/56807>. Acesso em: 22 set. 2016.

DUARTE, Rosália. Cinema \& Educação. 3. ed. Belo Horizonte: Autêntica, 2009.

FABRIS, A. A captação do movimento: do instantâneo ao fotodinamismo. ARS, São Paulo, v. 2, n. 4, fev./jun., 2004. Disponível em: <http://www.revistas.usp.br/ars/article/view/29 33/3623>. Acesso em: 22 set. 2016.

FANTIN, M. Crianças, Cinema e Mídia-Educação: Olhares e experiências no Brasil e na Itália. 2006. 409 f. Tese (Doutorado em Educação) Universidade Federal de Santa Catarina, Ilha de Santa Catarina - SC, 2006.

FERREIRA, M. C. O estudo das ciências no Brasil: resumo histórico do desenvolvimento científico no Brasil e sua ligação com a tecnologia e arte.

São Paulo: Edicon, 1989.

FOSSATTI, C. L. Cinema de animação: Uma trajetória marcada por inovações. In: ENCONTRO NACIONAL DE HISTÓRIA DA MÍDIA, 7., 2009, Fortaleza. Anais eletrônicos... Fortaleza, 2009. Disponível em:

<http://www.ufrgs.br/alcar/encontros-nacionais1/encontros-nacionais/7o-encontro-20091/CINEMA\%20DE\%20ANIMACaO\%20Uma\%20traj etoria\%20marcada\%20por\%20inovacoes.pdf>. Acesso em: 22 set. 2016.

FRESQUET, A.; MIGLIORIN, C. Da obrigatoriedade do cinema na escola, notas para uma reflexão sobre a lei 13.006/14. In: FRESQUET, A. (Org.). Cinema e educação: A lei 13.006. Belo Horizonte: Universo Produção, 2015. p. 425. Disponível em: <http://www.universoproducao.com.br/cineop/1 Ocineop_2015/Livreto_Educacao10Ci neOP_WEB.pdf>. Acesso em: 01 ago. 2016. LUCENA JÚNIOR, A. Arte da animação: técnica e estética através da história. 3. ed. São Paulo: Senac São Paulo, 2011. MAGALHÃES, M. Cartilha Anima Escola: técnicas de animação para professores e alunos. Rio de Janeiro, v. 2, 2015. Disponível em:
$<$ http://www.animaescola.com.br/media/arquivo s/material\%20pedag\%C3\%B3gico/animaescola_c artilha2015_web.pdf>. Acesso em: 13 mar. 2016. MOGADOURO, C. O cinema reinventando a escola - Um diálogo da Educomunicação com o filme A invenção de Hugo Cabret. C\&E, Vinte anos: uma trajetória para consolidar a Educomunicação no Brasil, São Paulo, v.19, n.1, jan/jun., 2014. Disponível em:

<http://www.revistas.usp.br/comueduc/article/vi ew/78568>. Acesso em: 27 nov. 2016.

MORAES, C. V. O. O. De um mundo da escola para uma escola do mundo: reflexão sobre meios e sobre fins. Comunicação \& Educação, São Paulo, v. 10, n. 3, set./dez., 2005. Disponível em: <http://www.revistas.usp.br/comueduc/article/vi ew/37543/40257>. Acesso em: 08 mar. 2016. MOTA, G. B. et al. O uso do filme de animação como ferramenta pedagógica no ensino básico de Presidente Prudente (SP). 2016. $161 \mathrm{f}$. Monografia (Trabalho de Conclusão de Curso em Jornalismo) - Faculdade de Comunicação Social "Jornalista Roberto Marinho", Universidade do Oeste Paulista (Unoeste), Presidente Prudente SP, 2016.

NAPOLITANO, M. Como usar o cinema na sala de aula. 4. ed. São Paulo: Contexto, 2006.

NISIO, F.. Pré-produção de um curta em stop motion. 2011. 45 f. Monografia (Graduação em Artes Plásticas) - Departamento de Artes Visuais, Universidade de Brasília (UnB), Brasília - DF, 2011.

PFROMM NETTO, S. A Odisseia do Cinema Educativo no Brasil. In: PFROMM NETTO, S. Telas que ensinam, Mídia e aprendizagem: do cinema às tecnologias digitais. 3. ed. Campinas: Alínea, 2011. p.101-124.

PIRES, E. G. A experiência audiovisual nos espaços educativos. Comunicação \& Educação, São Paulo, v. 13, n. 2, maio/ago., 2008. Disponível em: <http://www.revistas.usp.br/comueduc/article/vi ew/42298/45969>. Acesso em: 13 mar. 2016. PROCURANDO DORY. Direção: Andrew Stanton. Produção: Lindsey Collins. Roteiro: Victoria Strouse e Andrew Stanton. Música: Thomas Newman. Estados Unidos: Disney, 2016. 1 DVD (97 $\mathrm{min})$.

Recebido para publicação em 24/02/2017

Revisado em 29/04/2017

Aceito em 06/06/2017 